\title{
FC/Battery Power Management for Electric Vehicle Based Interleaved dc- dc Boost Converter Topology
}

\author{
A. Benrabeh ${ }^{1}$, F. Khoucha ${ }^{1,2}$, O. Herizi ${ }^{1}$, M.E.H. Benbouzid ${ }^{2}$ and A. Kheloui ${ }^{1}$ \\ ${ }^{1}$ Ecole Militaire Polytechnique, 16111 Algiers, Algeria. \\ ${ }^{2}$ University of Brest, EA 4325 LBMS \\ Rue de Kergoat, CS 93837, 29238 Brest Cedex 03, FRANCE \\ E-mail of Corresponding Author: benrabah.abdeldjabar@hotmail.fr fkhoucha04@yahoo.fr
}

\section{Keywords}

Fuel cell System (FCS), Electric vehicle, Energy management, Interleaved Boost DC-DC Converter (FC-IBC).

\begin{abstract}
Due to the fact that the environmental issues have become more serious recently, interest in renewable energy systems, such as, fuel-cells (FCs) has increased steadfastly. Among many types of FCs, proton exchange membrane FC (PEMFC) is one of the most promising power sources due to its advantages, such as, low operation temperature, high power density and low emission. However, using only PEMFC for electric vehicle may not be feasible to satisfy the peak demand changes especially during accelerations and braking. So, hybridizing PEMFC and an energy storage system (ESS) decreases the FC cost and improves its performance and life. Battery (B) appears to be the most powerful candidate to hybridize with PEMFC for vehicular applications. Therefore, the performance of PEMFC/B hybridization is limited considerably by the performance of the converter. Thus, a suitable dc-dc converter topology is required. Various isolated and nonisolated converter topologies for FC applications have been proposed in literature. The objective of this study is to design and simulate a fuel cell - interleaved boost dc-dc converter (FC-IBC) for hybrid power systems in electric vehicle application, in order to decrease the FC current ripple. Therefore Energetic efficiency can also be improved. A control strategy capable of determining the desired FC power and keeps the dc voltage around its nominal value by supplying propulsion power and recuperating braking energy is designed and tested with an urbane electric vehicle model.
\end{abstract}

\section{Introduction}

Fuel Cell (FC) technologies are expected to become an attractive power source for automotive applications because of their cleanness, high efficiency, and high reliability. FCs are electrochemical devices that directly convert the chemical energy of fuel into electricity. There are different kinds of FCs characterized by their electrolytes. One of the most promising to be utilized for stationary or transported applications is the polymer electrolyte membrane FC (PEMFC) due to its relative small size and simple design. It has too high power density with lower operating temperatures when compared to other types of FC systems [1]-[2].

Although FC systems exhibit good power capability during steady-state operation, the dynamic response of FCs during transient and instantaneous peak power demands is relatively slow. Therefore, to improve the performance of the FC system during transient and instantaneous peak power demands in electric vehicle application, the FC system is always associated with energy storage systems (ESS) (e.g., batteries and/or supercapacitors). The ESS can be used to recover energy through regenerative braking [3]-[4]. For these applications, a high-power dc/dc converter is a key element that interfaces the FC or ESS with the dc bus in the powertrain of the EVs. Therefore, the design of high-power dc/dc converters and their controller play an important role to control power regulation particularly for the FC. The advantages and disadvantages of several topologies of $\mathrm{dc} / \mathrm{dc}$ converters, based on their 
component count, are presented and compared in [5]-[6]. Furthermore, for high-power applications, IBC converters have been proposed for use in electric vehicle applications [7].

The FC Electric Vehicle (FCEV), as shown in Fig. 1, utilizes an FC as the main power source and the ESS (Batteries) as the auxiliary power source to assist the propulsion of the vehicle during transients and to recuperate energy during regenerative braking. In this configuration, the FC is connected to the $\mathrm{dc}$ bus through an IBC, whereas the ESS is connected to the dc bus via a bidirectional $\mathrm{dc} / \mathrm{dc}$ converter. As was mentioned in much of the literature, the $\mathrm{dc} / \mathrm{dc}$ converter is one of the most important components in a FC powered system. It allows a desired level of dc voltage to be obtained without having to increase the stack size. As a result, this research will focus on a nonisolated $\mathrm{dc} / \mathrm{dc}$ converter that interfaces the FC with the powertrain of EVs. In high-power boost converters, the major design aspect is the selection of the boost inductor and the output capacitor. The major concern is the size, cost, and weight of such a high-power inductor that is generally the single heaviest component in the entire $\mathrm{dc} / \mathrm{dc}$ converter. To reduce the inductor size and weight, a small inductance value is preferred. In addition, the dc/dc converter performance directly influences the characteristics of the FC stack.

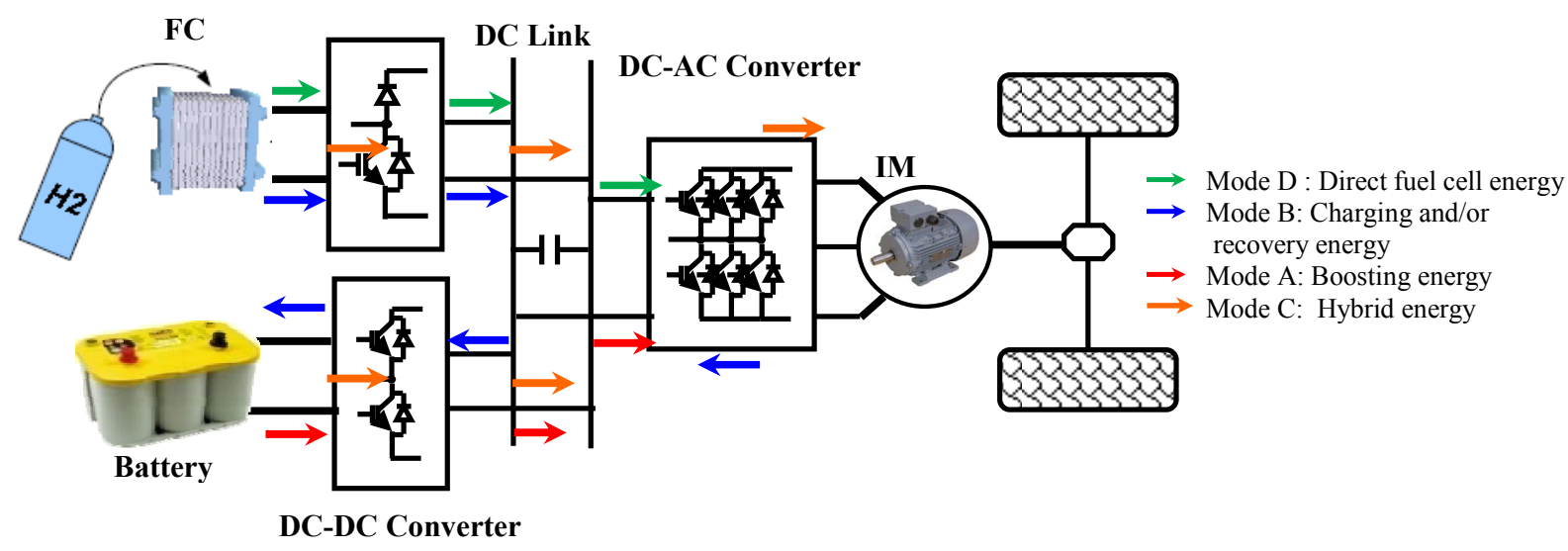

Fig. 1: Block diagram of the FCEV

Indeed, the ripple and harmonic content of the current is one of the various phenomena influencing FC lifespan as well as battery lifetime [8], [9]. The main objective of this paper is to minimize inductor size, capacitor by the converter design and current ripples, and harmonic content by both the converter design and control.

This paper introduces firstly, the dynamic electric powertrain of a FCEV. In the second part, simple digital current sharing method based FC-IBC is used to improve power distribution during transient and instantaneous vehicle peak power demands.

\section{Fuel cell system (FCS) model}

The electrochemical reaction at the membranes is assumed to occur instantaneously. The fuel cell stack (st) model contains four interacting sub-models: the stack voltage model, the anode flow model, the cathode flow model, and the membrane hydration model. It is assumed that the stack temperature is constant at $80^{\circ} \mathrm{C}$. The voltage model contains an equation to calculate stack voltage based on fuel cell pressure, temperature, reactant gas partial pressures and membrane humidity. PEMFCs combine hydrogen and oxygen over a platinum catalyst to produce electrochemical energy with water as the byproduct. Fig. 2 shows the (V-I) characteristic of a typical single cell operating at room temperature and normal air pressure. 


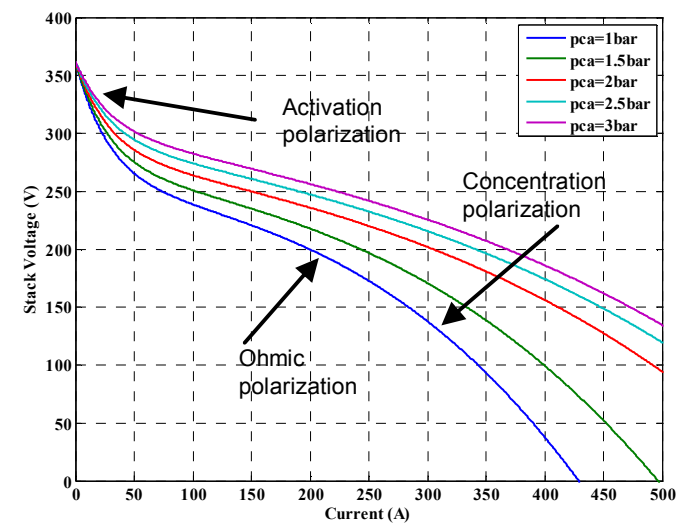

Fig. 2: Fuel cell polarization curve fitting results at $80^{\circ} \mathrm{C}$.

The variation of individual cell voltage is found from the maximum cell voltage (or EMF) and the various voltage losses. Multiple factors contribute to the irreversible losses (voltage drop) in real fuel cell that cause the cell voltage to be less than its ideal potential [10]. The losses, which are also called polarization, irreversibility, or over voltage, over potential, originate primarily from three sources: a) activation polarization, $b$ ) ohmic polarization, and $c$ ) concentration (mass transport) polarization. Each of these is associated with a voltage drop and they are dominant in different regions of current density. Fig. 2 shows the different regions and the corresponding polarization effects. The ideal voltage is the maximum voltage that each cell in the stack can produce at a given temperature with the partial pressure of the reactants and products known. The output voltage of a single cell can be given by [11], [12]:

$$
V_{f_{c}}=E-v_{a c t}-v_{o h m}-v_{c o n c}
$$

\section{Battery Model}

The central element of EV and of more electric systems in general is the battery. This element stores a great amount of energy to be release when necessary. The battery enables regenerative braking in an EV and allows supplementing a slow dynamic energy source, such as the fuel cell. Benefits are drawn from these features in EVs based on fuel cells. The battery's management system (BMS) must ensure an efficient management battery's state of charge (SOC). To accomplish this, the designer of the BMS must have a detailed simulation of the EV's traction system including a detailed model of the battery. In this paper, we used the block "Battery" available in the library of MATLAB/Simulink. It represents most popular types of rechargeable batteries. The battery voltage is described by the following equation [13]:

$$
V_{b a t t}=E_{0}-R i-K \frac{Q}{Q-i t} i t+A \cdot \exp (-B . i t)-K \frac{Q}{i t-Q} i^{*}
$$

\section{Where:}

$V_{\text {batt }}$ is the battery voltage $(\mathrm{V})$

$E_{0}$ is battery constant voltage $(\mathrm{V})$

$R$ is the internal resistance $(\Omega)$

$i$ is the battery current (A)

$K=$ polarization constant $(\mathrm{V} / \mathrm{Ah})$ or polarization resistance $(\Omega / \mathrm{Ah})$

$Q=$ battery capacity (Ah)

$i t=\int i d t$ is the actual battery charge (Ah)

$A$ is the exponential zone amplitude (V)

$B$ is the exponential zone time constant inverse $(\mathrm{Ah})^{-1}$

$i *$ is the filtered current (A) 
The particularity of this model is the use of a filtered current $\left(i{ }^{*}\right)$ flowing through the polarisation resistance which solve also the algebraic loop problem due to the simulation of electrical systems in Simulink, also the simplicity with which the dynamic model parameters are extracted. In fact, it is not necessary to take experimental measures on the battery in order to extract the parameters. Only three points on the manufacturer's discharge curve, in steady state, are required to obtain the parameters. Battery manufacturers provide datasheet which includes a "Typical Discharge Characteristics" curve where it is possible to extract the fully charged voltage $\left(\mathrm{V}_{\text {ful }}\right)$, the end of the exponential zone $\left(\mathrm{Q}_{\text {exp }}\right.$, $\left.\mathrm{V}_{\text {exp }}\right)$, the end of the nominal zone $\left(\mathrm{Q}_{\text {nom }}, \mathrm{V}_{\text {nom }}\right)$ (when the voltage starts to drops abruptly) and the maximum capacity $(\mathrm{Q})$. Also, the internal resistance $(\mathrm{R})$ is generally given.

With these three points, it is possible to solve, using equation 1 , the following set of equations (equations 3, 4 and 5).

$$
\begin{aligned}
& V_{\text {Full }}=E_{0}-R i+A \\
& V_{\exp }=E_{0}-R i-K \frac{Q}{Q-Q_{\exp }}\left(Q_{\exp }+i\right)+A \cdot \exp \left(\frac{-3}{Q_{\exp }} Q_{\exp }\right) \\
& V_{\text {nom }}=E_{0}-R i-K \frac{Q}{Q-Q_{\text {nom }}}\left(Q_{\text {nom }}+i\right)+A \cdot \exp \left(\frac{-3}{Q_{\text {nom }}} Q_{\text {nom }}\right)
\end{aligned}
$$

This general approach can be applied to other battery types to obtain the model parameters [13]. Obviously, these parameters are approximate and the level of accuracy of the model depends on the precision of the points extracted from the discharge curve.

Fig.3 shows the simulated discharge characteristics curves for a Yuasa Np18-12 lead acid battery for various discharges current.

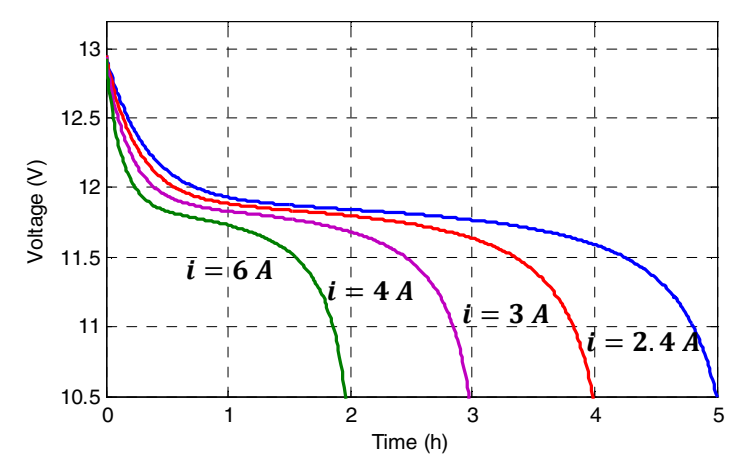

Fig. 3 Battery discharge characteristics

\section{FC Interleaved boost converter topology and operation}

Fig. 4 shows the power stage of a fuel cell system. The main role of this power stage is to boost the fuel cell voltage to be within the operating range of that of the DC bus, and to regulate the fuel cell output power according to the power control strategy. Another significant goal is to achieve lower fuel cell output current ripple at high frequencies. The power stage consists of a two interleaved boost converters connected in parallel sharing a common DC bus. Each boost converter consisted of an input inductor $L_{k}$, a static switch $\left(S_{k}\right)$ controlled by the binary input signal $u_{k}$, and an output diode $D k(k=1$, 2). Each diode cathode is connected to the same point with the output capacitor $C$ in parallel with the dc electric load represented by a pure resistance $R$, this according to the input impedance of the DC bus. 
As shown in Fig. 5, the switch gate signals for the phases are exactly shifted by $360 \circ \mathrm{N}(\mathrm{N}$ is the number of phases, here $\mathrm{N}=2$ ). The two current phases have the same waveform (Fig. 6), except that they are shifted 180. The ripple in the low voltage side current $i_{T}$ (Fig. 3), which is the sum of the two low side phase-currents, is significantly reduced due to harmonic elimination. Furthermore, the frequency of the ripple in $i_{T}$ is increased to $20 . f_{s}$ ( $f s$ is the switching frequency). Because of lower current ripple and less harmonic content, the size of the filter capacitance on the low voltage side can be reduced, or even removed. The filter capacitance on the high side is composed of two capacitors. Each one is placed physically close to its phase, in order to reduce the parasitic inductance between the switch and the capacitor. Each phase processes only the half of the total power, which, therefore, reduces the stress on the switching devices and allows fault tolerant control.

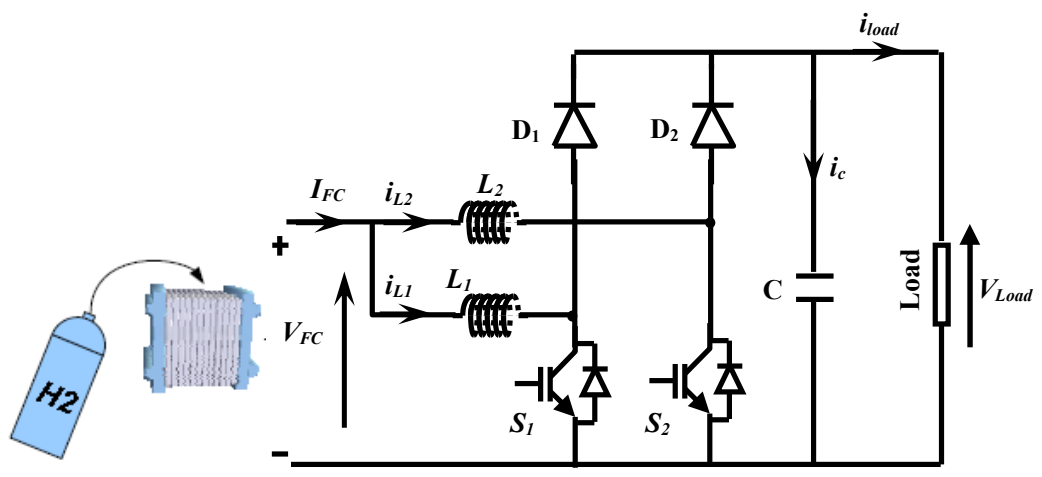

Fig. 4: The 2 Phase Interleaved DC Boost Converter.
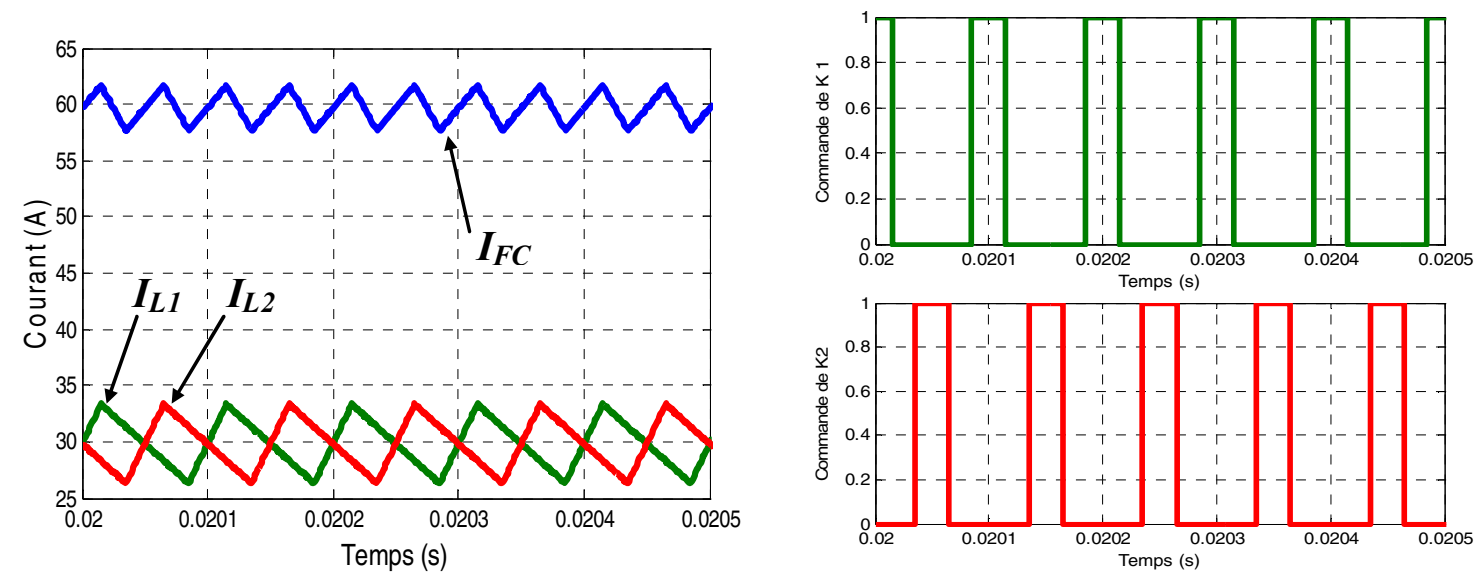

Fig. 5: Current waveforms of the converter and switch gate signals

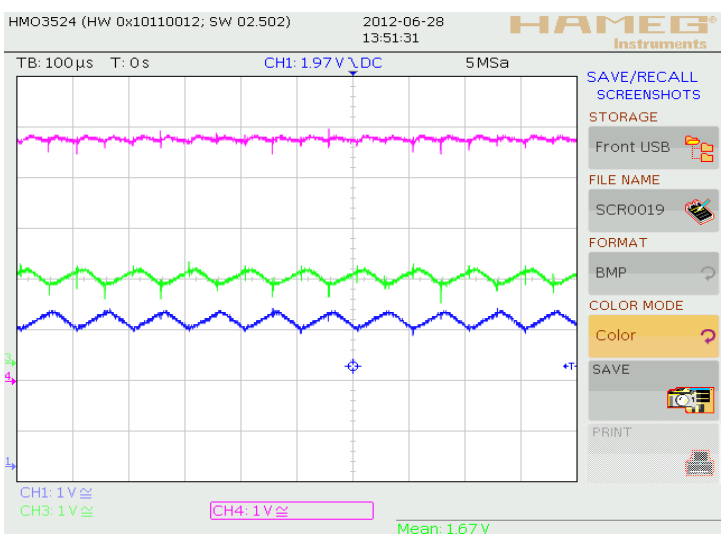

Fig. 6: Experimental Current waveforms 
Other possible choices mainly include typical boost converter, which uses least number of switch components. But the disadvantage is obvious, due to the large size of passive components and high current ripple. There also exist a series of high power converters with isolated topologies, such as the forward converter with step-up transformer. These converters usually contain transformers and more than 2 semiconductor devices, which lead to inadequate reliability and high cost. Furthermore, when considering the Cuk converter, it requires much more passive elements, which is not very attractive.

\section{Power Management for FC-Battery hybrid power system}

FC is more efficient and sustainable when operating in the normal load region. There are two ways to maintain the FC operating point within the desired region. The first approach is to apply proper amount of load to the system, such that the power provided by the FC is located on the normal load region on the polarization curve. The first approach is entirely load dependent and nearly not applicable in a dynamic situation. The second approach is to properly control current of both FC and secondary power source, such that FC operation point is forced or naturally falls into the normal load region on the polarization curve (Fig. 2).

FC system cannot respond to load dynamics well (high-inertia system); therefore, the role of primary source is suitable for FC, providing base power to the load. Battery, as an excellent candidate for secondary source, can react to fast dynamics and contribute to load peaking. However, battery can only store finite amount of energy, and state of charge (SOC) has to be recovered above certain level for extended battery life.

Therefore, for a stand-alone FC-battery hybrid power system, the role of primary source and secondary power source should not be fixed; a more flexible configuration has to be proposed to accommodate the variety of system component status and different load scenarios (quick start, Accelerations and deceleration).

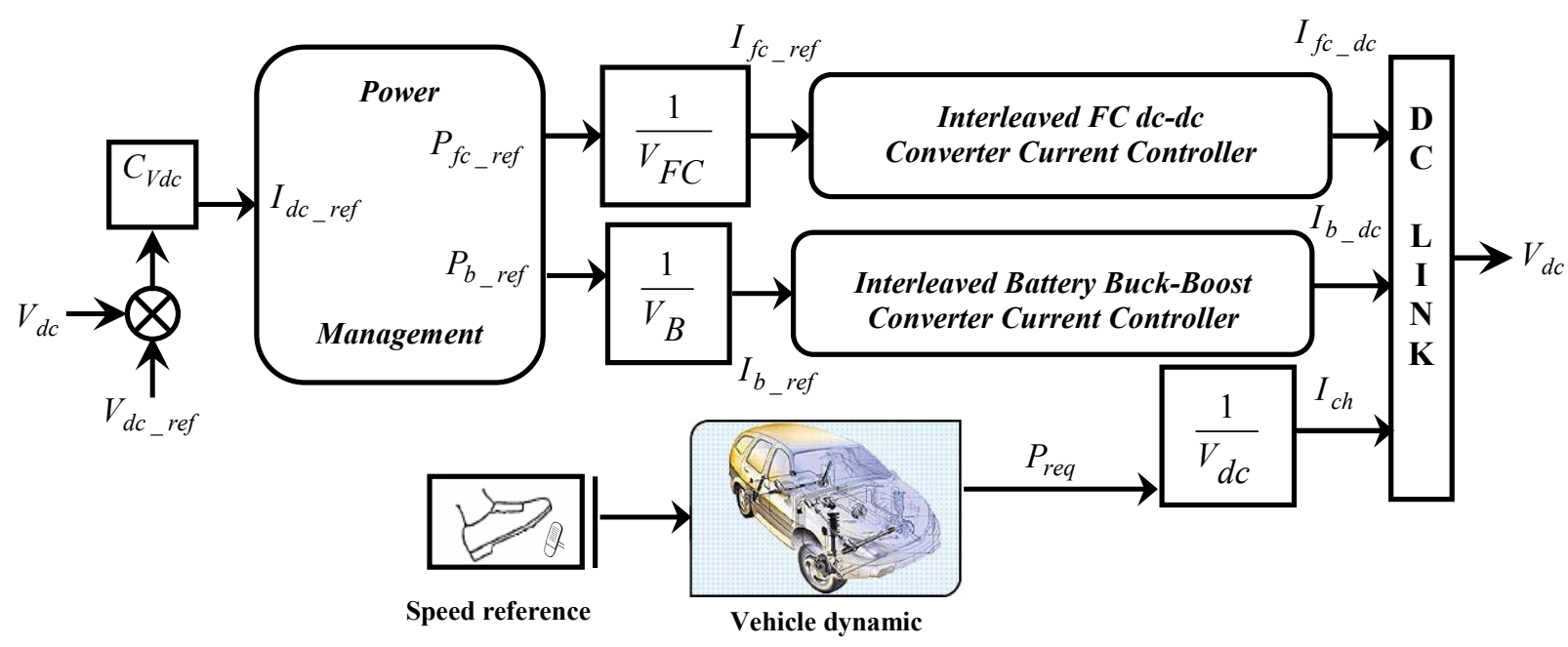

Fig. 7: Power management and current control structure

The powertrain configuration and power management strategy is illustrated in Fig. 1. The control system collects the data from fuel cell, battery, and motor system, and generates an optimized power distribution, based on a designed power control strategy according to the reference power values. Four modes of operation are defined for the FC-battery hybrid power system for electric vehicle application. Since FC has a relatively long start-up period to reach the proper chamber temperature for chemical reaction, the system will start with battery as the main power source in Mode A; a very small amount of current is drawn from FC for a more efficient warm up. 
Based on the status of FC (start-up process) and battery SOC, system goes to recover Mode B. During this mode, FC charges the battery and supplies light load to prepare for load peaking demand. When battery SOC rises to a certain level, the system is ready to work in Mode C; during this mode of operation, FC and battery share the load dynamically with different power output based on desired operating point of FC and battery SOC. After battery SOC lowers to the preset value and load demand is relieved, battery channel is shut down and FC delivers up to full power to supply the load, which is indicated by Mode D. The four operating modes do not necessarily take place in the same sequence. The roles of primary source and secondary power source are assigned in a flexible manner such that the performance and sustainability of the hybrid power system can be guaranteed over the entire range of vehicle speed variation.

This energy management strategy, represented in Fig. 7, was tested on Standard Driving Cycle: The speed profile (Fig. 8), representing urban and highway scenarios, is widely used in the literature to evaluate the performance of energy management strategies.

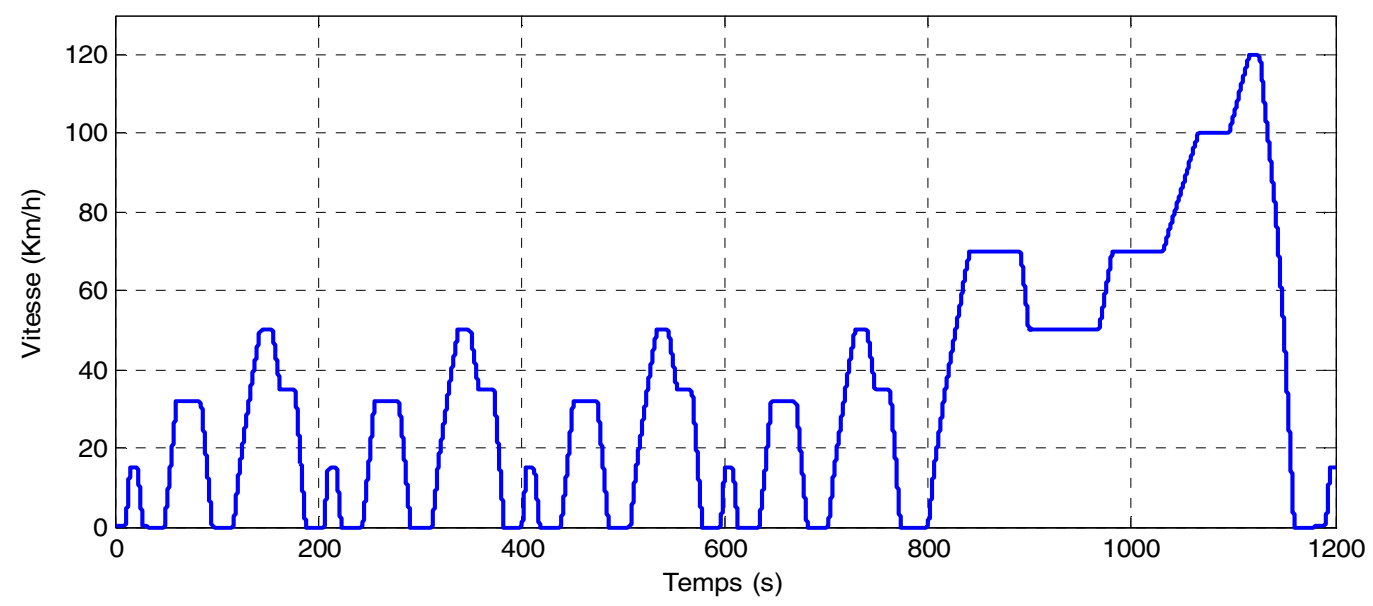

Fig. 8: Speed profile

To illustrate the behaviour of the proposed strategy, the simulation results corresponding to the driving cycle are shown: the power split between the fuel cell system and the energy storage system, and the evolution of the SOC in the ESS are shown in Fig. 9, Fig. 10, and Fig. 11.

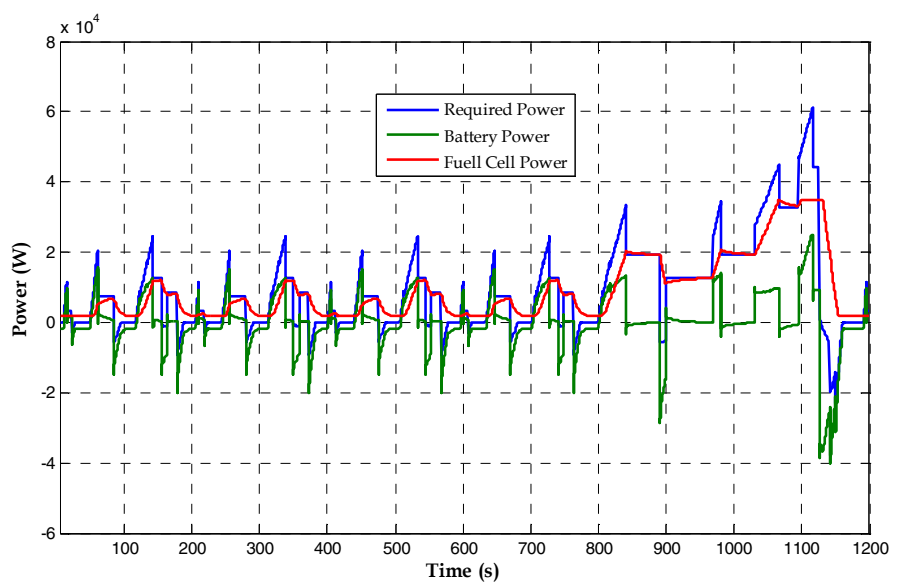

Fig. 9: Power flow management 

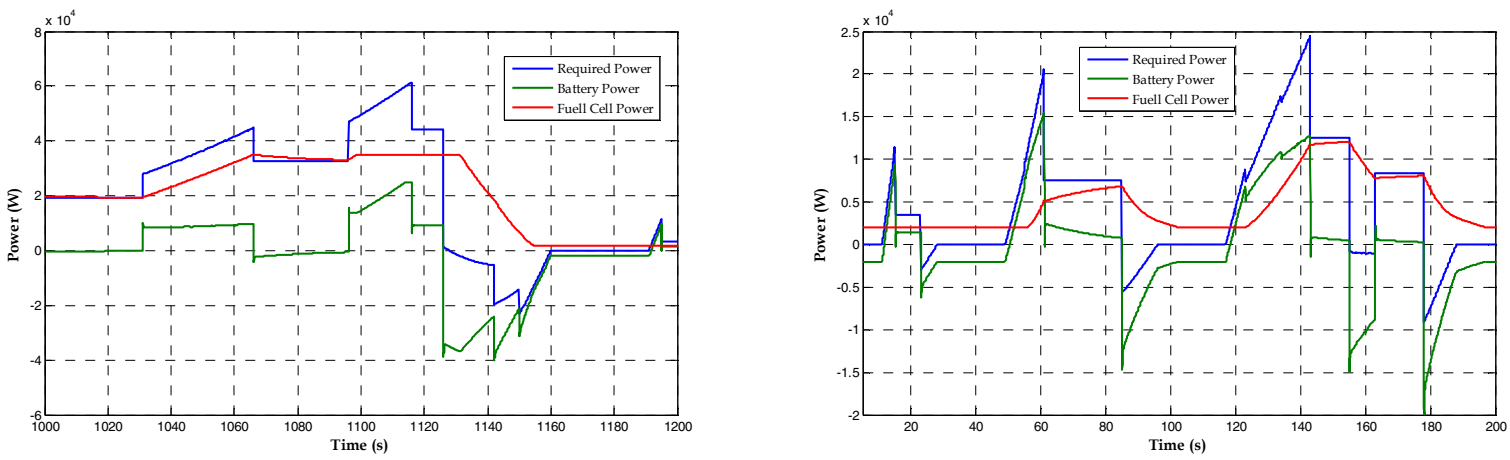

Fig. 10: Power management curve at high and low speed

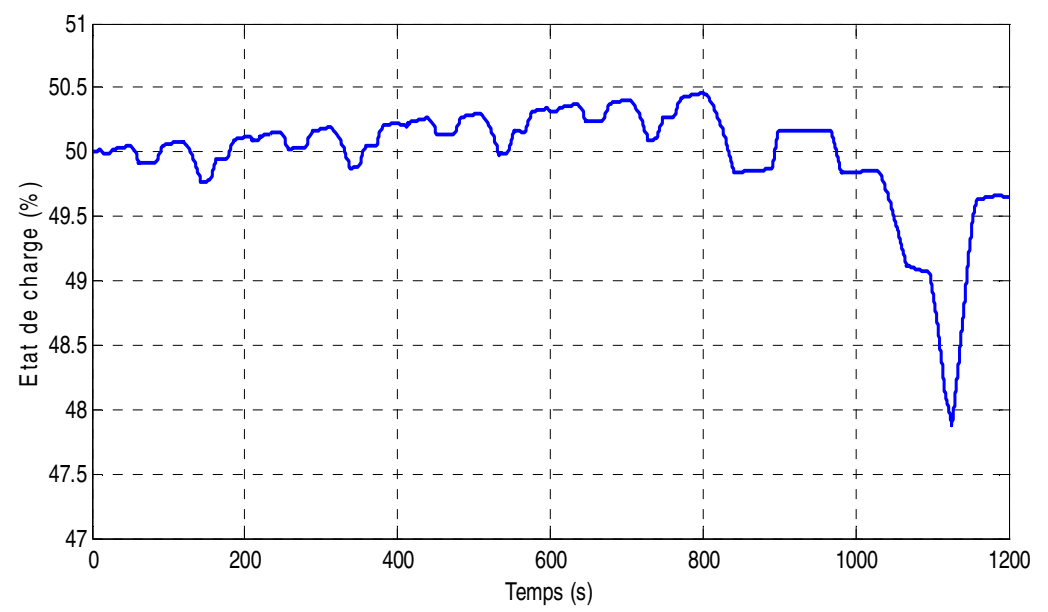

Fig. 11: The evolution of the SOC

It is remarkable that it is possible to recover energy from regenerative braking, allowing a considerable improvement in the hydrogen economy. The recovered energy from regenerative braking may represent an important fraction of the economy improvement. However, the amount of energy that is possible to recover is strongly dependent on the driving profile. In urban driving cycles, in which there is considerable braking, the percentage of regenerated energy is much greater than in non-urban cycles where this percentage is quite small.

The dynamics of FC are relatively slow, mainly because of the dynamics of the air compressor and the manifold-filling dynamics [14]-[15]. Batteries are essential to providing the additional power during the sharp load-transients. The state of charge changes over the driving cycle resulting in a gain or a loss of energy in the ESS.

\section{Conclusion}

This paper presents a FC-IBC /battery hybrid power system analysis and design for electric vehicle application. Different modes power management are discussed. Modes of operation for an efficiently operated FC-battery power system are defined, presented, and implemented. The FC-IBC converter system is designed and modelled, active current sharing and power management control system is designed to accommodate FC status, battery SOC, and vehicle power demand. Dynamic and steadystate results are provided to prove the feasibility of the system design. 


\section{References}

[1] T.V. Nguyen and R.E. White : A Water and Heat Management Model for Proton-Exchange-Membrane Fuel Cells, Journal of Electrochemical Society, vol.140, no.8, pp.2178-2186, 1993.

[2] M. W. Ellis, M. R. Von Spakovsky, and D. J. Nelson: Fuel cell systems: Efficient, flexible energy conversion for the 21st century, Proc. IEEE, vol. 89, no. 12, pp. 1808-1818, 2001.

[3] A. Emadi, Y. J. Lee, and K. Rajashekara : Power electronics and motor drives in electric, hybrid electric, and plug-in hybrid electric vehicles, IEEE Trans. Ind. Electron., vol. 55, no. 6, pp. 2237-2245, Jun. 2008.

[4] A. Payman, S. Pierfederici, and F. Meibody-Tabar : Energy management in a fuel cell/supercapacitor multisource/multiload electrical hybrid system, IEEE Trans. Power Electron, vol. 24, no. 12, pp. 2681-2690, 2009.

[5] M. Al Sakka, J. Van Mierlo, H. Gualous, and P. Lataire : Comparison of 30KW DC/DC Converter topologies interfaces for fuel cell in hybrid electric vehicle, in Proc. 13th Eur. Conf. Power Electron. Appl., Barcelona, Spain, Sep. 8-10, 2009.

[6] O. Hegazy, J. Van Mierlo, and P. Lataire : Analysis, control and implementation of a high-power interleaved boost converter for fuel cell hybrid electric vehicle, Int. Rev. Electr. Eng., vol. 6, no. 4, pp. 1739-1747, 2011.

[7] P. Thounthong and S. Pierfederici : A new control law based on the differential flatness principle for multiphase interleaved DC-DC converter, IEEE Trans. Circuits Syst II, Exp. Briefs, vol. 57, no. 11, pp. 903907, 2010.

[8] K. Jin, X. Ruan, M. Yang, and M. Xu : A hybrid fuel cell power system, IEEE Trans. Ind. Electron., vol. 56, no. 4, pp. 1212-1222, Apr. 2009.

[9] M. Kabalo, B. Blunier, D. Bouquain, and A. Miraoui : State-of-the-art of DC-DC converters for fuel cell vehicles, in Proc. IEEE Vehicle Power and Propulsion Conf., Lille, France, Sep. 1-3, 2010, pp. 1-6.

[10] J.C. Amphlett et al. : Performance modeling of the Ballard Mark IV solid polymer electrolyte fuel cell: II. Empirical model development, Journal of Electrochemical Society, vol. 142, n¹, pp. 9-15, 1995.

[11] J.H. Lee et al., "Modeling electrochemical performance in large scale proton exchange membrane fuel cell stacks," Journal of Power Sources, vol. 70, n² 2, pp. 258-268, February 1998.

[12] D. Rezzak, F. Khoucha, M.E.H. Benbouzid, A. Kheloui and A. Mamoune : A DC-DC converter-based PEM fuel cell system emulator," in Proc. International Conference Power Engineering, Energy and Electrical Drives (POWERENG 2011), Malaga, May 11-13, 2011.

[13] O. Tremblay, A. Dessaint : Experimental Validation of a Battery Dynamic Model for EV Applications, World Electric Vehicle Journal Vol. 3 - ISSN 2032-6653. Stavanger, Norway, May 13 - 16, 2009.

[14] V. Tsourapas, A. G. Stefanopoulou, J. Sun : Model-Based Control of an Integrated Fuel Cell and Fuel Processor With Exhaust Heat Recirculation, IEEE Trans. Power Electron, vol. 15, no. 2, pp. 233-245, 2007.

[15] O. Hegazy, J. Van Mierlo, P. Lataire : Analysis, Modeling, and Implementation of a Multidevice Interleaved DC/DC Converter for Fuel Cell Hybrid Electric Vehicles ,IEEE Trans. Control systems technology, vol. 27, no. 11, pp. 4445-4458, 2012. 